Journal of Development and Communication Studies, Vol. 7. Nos. 1 \& 2, January- December, 2020 ISSN (Online \& Print): 2305-7432.

http://www.devcomsjournalmw.org

\title{
Perception of HIV/AIDS infection and its effect on condom use among the youth of Kenya's Kibera Slum
}

\author{
Jeremiah M. Nganda, Leah Jerop Komen \& Beatrice Mbogoh, Daystar University, \\ Nairobi, Kenya. Corresponding author email: jeremynganda@gmail.com
}

\begin{abstract}
While studies have shown that the total number of new HIV / AIDS infections globally is on the decrease, many Sub Saharan countries continue to record high HIV prevalence. This is the case especially among the youth living in informal settlements such as Kibera slums in Kenya. Proper and consistent condom use has been presented as one of the best ways of preventing the transmission of HIV among the youth whereas abstinence has been found to be a challenge for the youth who are seen as sexually active. Though several behaviour change campaigns have been done in Kenya to promote the use of condoms among the youth, their uptake is still low (Coma, 2014). Consequently, this study sought to find out the factors were influencing condom use decisions among the youth. Using the Theory of Planned Behaviour that links behaviour change to intention to perform behaviour greatly influenced by attitude, social norms and perceived behavioural control. Data for this quantitative study was collected through a questionnaire administered to 400 youths in Kibera and 356 were completed. Data collected were keyed into SPSS for analysis and presented in tables and graphs. Findings of the study revealed that many of the youth were sexually active (51 per cent) but were not using condoms. Their perception was that they were at no risk of infection (53.2 per cent). This perception of not being at risk impedes condom use among the youth hence the high HIV prevalence while another group felt that the free distributed condoms were of low quality. The study recommends that communicators, especially in this era of new media should tailor campaigns to address the perception of youth towards condoms. In addition, condom communication campaigns should link condom use to perception of risk of infection.
\end{abstract}

Key words: Condoms, HIVIAIDS, youth, perception, Kenya, Kibera https://doi.org/10.4314/jdcs.v7i1-2.3

(C) 2020. The Author. This work is licensed under the Creative Commons Attribution 4.0 International License (CCBy-NC-ND). Users may freely share and redistribute this work provided that the author and the Journal of Development and Communication Studies are fully acknowledged. Users may not tweak or remix and offer this work for sale. The full license may be accessed at https://creativecommons.org/licenses/by-nc-nd/4.0/ 


\section{Introduction}

Acquired Immune Deficiency Syndrome (AIDS) is still one of the leading causes of death worldwide, more than thirty years since the first case was reported (Friedland, 2016). In 2014, the United Nations Programme on HIV/AIDS (2015) reported that over 36 million people were living with HIV and another nearly 18 million people were on antiretroviral treatment.

Despite the large number of people infected by the disease, cases of new infections are being reported in many nations. In 2013, for instance, there were more than two million new infections, 75 percent of which were concentrated in only 15 countries, with Kenya being among those countries and among the top ten countries in Africa in terms of HIV burden (UNAIDS, 2014). This implies that the rate of new infections among the Kenyan population is still high.

HIV/AIDS is a disease with no confirmed cure yet, and unfortunately, only a fraction of those infected are able to access anti-retroviral drugs. This makes prevention a top priority especially among the youth of 15 to 24 years (Puffer et al., 2011). The youth are more vulnerable because of their high-risk behaviour. There are several behavioural and social factors that make youth a high risk category in terms of infection with HIV/AIDS. These include early sex debut, many sexual partners, cross-generational sex partners, proneness to engaging in unprotected sex, and engaging in sex for monetary gain among others (Mavedzenge et al., 2011a; as cited in Santelli, Speizer, \& Edelstein, 2013).

HIV can be transmitted in many ways. Some of the methods of transmission are sexual intercourse, sharing of needles or other equipment used for injection, mother to child and through coming into contact with contaminated blood. Transmission through sexual intercourse is the method that has received most of the focus from researchers, perhaps because it is estimated that close to 90percent of all new HIV/AIDS infections in sub-Saharan Africa are sexually transmitted (Cohen, 2004).

Safe sex, which Stutterheim, Bertens, Mevissen, and Schaalma (2013) defined as correct and consistent condom use has been presented as one of the best options in stopping the spread of HIV/AIDS. When condoms are used consistently and in the right way, the risk of contracting HIV/AIDS is lowered greatly hence lower levels of HIV prevalence. Practicing safe sex depends on an individual's ability and willingness to choose to use condoms. According to Sheeran, Abraham, and Orbell (1999; as cited in Stutterheim et al., 2013), willingness to use condoms is determined by attitude of the user towards condoms, social norms and self-efficacy towards condom use by the sexually active youths.

The effort by government and non-governmental organizations to combat the effect of HIV/AIDS is evident in the several aggressive behaviour-change communication campaigns that have been carried out in Kenya targeting to change the sexual behaviour of the youth. Wandera (2013) lists some of the communication interventions done in Kenya aimed at addressing sexual behaviour of teenagers and youth as "Nimechill" meaning "I am abstaining", the famous television programme "Shuga" and "je una yako?" which means "do you have yours". Most of these campaigns 
have focused on providing youth with information on what they need to know to stay safe from HIV/AIDS.

Despite the various communication interventions that have been carried out, young people are still engaging in risky sexual behaviour. According to the World Health Organisation (WHO, 2013), in 2012, it was estimated that three in every ten new infections were among people aged between 15 and 24 years. Recent reports indicate that 15 to 24 year-olds contributed 51 percent of new infections among Kenyan adults in 2015 (NACC, 2016). Eighty percent of Kibera's population is either infected or affected by HIV/AIDS (Chege \& Mwisukha, 2013). Kibera's HIV prevalence has been reported to be 12.6 percent which is almost more than double the country average prevalence of 6.2 percent (Edwards et al., 2015). This high HIV prevalence rate is fuelled by poverty and low condom use.

A study by Coma (2014) found that although 72 percent of the respondents reported to have access to condoms, only 11.1 percent of men and 26.3 percent of women reported condom use in their last sex encounter. This is despite the several communication interventions that have been done to address the issue. It has not been easy to understand why there is still low condom use despite the many campaigns that have sought to educate people on benefits of using them. While the youth have information regarding HIV/AIDS, statistics on the uptake of condoms counters their knowledge. There is need to establish what impedes the uptake of condoms among the youth. This paper examines the perception of youth towards risk of HIV/AIDS infection and how it affects their condom use decisions.

\section{Literature Review}

\section{Youth are Sexually Active}

Coma (2014), in a study in rural Kenya, noted that from the respondents contacted for the study, the median age for sex debut was 15 years for females and 12.5 years for males. This corroborates a study done in the United States of America (USA) which found that almost half of high school students were sexually active (CDC, 2012; as cited in Haley, Puskar, Terhorst, Terry, \& Charron-Prochownik, 2013). According to Ndati (2013), seven out of ten girls and eight out of ten boys had engaged in sex before 20 years of age. Kenyan adolescents and youths are sexually active; reports have shown that 70 percent of pregnancies in Kenya are in ages 15 to 24 years (NACC, 2015).

\section{New Infections High among the Youth}

Adolescents comprise a substantial number of new infections of STIs all over the world. A study in the US showed that 50 percent of new infections of sexually transmitted diseases were among the adolescents (Weimstock, Berman \& Cates, 2004 as cited in Ritchwood, Ford, DeCoster, Lochman, \& Sutton, 2015). A report on the Kenya Aids Strategic Framework released in April 2016 indicated that HIV prevalence among the youth is significantly high and number of new infections is on the rise (Githugo, 2016). NACC (2015) reported that 29 percent of new infections in Kenya were among the youth. 


\section{Low Condom Use Despite a lot of Awareness Creation}

Studies done in Kenya have confirmed low condom use among youths, despite the fact the condoms are easy to access and youths have sufficient knowledge about the use of condoms. A study by Coma (2014) revealed that although 72 percent of respondents reported to have access to condoms, only 11.1 percent males and 26.3 percent females reported condom use in their last sex encounter. This corroborates studies done in the USA among high school students that showed that despite knowledge on effectiveness of condoms, nearly 40 percent of youths were sexually active but not using condoms (Haley et al., 2013). Previous studies in Kenya have shown that the knowledge about HIV/AIDS is high. Ndati's (2013) study established that four in every five 15 to 19 years old were aware that someone who looks healthy could be infected with the AIDS virus.

As shown in the paragraphs above, the number of new HIV infections among the youth are high. Despite the many campaigns that have been done creating awareness on why condoms should be adopted, studies show many sexually active youth are not using condoms. There could be many reasons on why the youth are not using condoms. Key among them is perception towards condoms.

There are many theories of behaviour prediction and change. Some of them are: Social Cognitive Theory which proposes that people regulate their own behaviours instead of merely reacting to what the surrounding environment dictates, the Health Belief Model which limits behavioural influence to attitude and beliefs, Theory of Reasoned Action which does not predict behaviour that is not under rational control of the individual and Theory of Planned Behaviour among others. Studying the behaviour prediction theories carefully shows that there are only a restricted number of variables that are useful in understanding any behaviour. The Theory of Planned Behaviour best captures the key determinants of behaviour change.

\section{Theoretical context}

The Theory of Planned Behaviour (TPB) was introduced by Icek Ajzen (1985) as an extension of the Theory of Reasoned Action (TRA) (Fishbein \& Ajzen, 1975; as cited in Ajzen, 1985). TRA is said to have been useful in explaining human behaviour, however, it failed in predicting behaviour that was not under full rational control of the person performing the behaviour (Hsu \& Huang, 2012). This led to the inclusion of Perceived Behavioural Control (PBC) into the TRA forming the TPB. This addition made it possible to account for possible constraints as perceived by the individual performing the behaviour (Hsu \& Huang, 2012).

Intention is the key determinant of whether certain behaviour will be performed or not (Ajzen, 1985). Behavioural intention, according to Ajzen (1985) is a function of three key determinants, namely, attitude, subjective norm and PBC. Attitude, which is a key construct in TRA and TPB, refers to an individual's valued inclination to behave in a certain way towards a given target (Ajzen, 1985; Hsu \& Huang, 2012). 
The second key determinant of intention under TPB is subjective norms. This refers to an individual's perception on whether or not to perform a certain behaviour based on influence of his or her social references (Hsu \& Huang, 2012). Conner and Armitage (1998) explained it as the pressure on an individual from his or her social circles to perform or not perform a given behaviour. This implies that there are instances where individuals consider the opinions of their friends and family before performing a given behaviour.

The third key determinant of intention under TPB, according to Ajzen (1985) is PBC. This has been defined as someone's perception of one's capability to perform a specific behaviour, specifically perceptions of ease of difficult in performing a given behaviour (Hsu \& Huang, 2012; Conner \& Armitage, 1998). The intention to perform any behaviour is subject to be faced by constraints. PBC suggests that people are expected to perform behaviours that they consider to have control over (Conner \& Armitage, 1998).

Based on the determinants of intention under TPB highlighted above, then it can be said that human beings will probably perform a given behaviour if they believe it will lead to a valuable result, that the people they look up to will approve the behaviour and that they have the skills and abilities to perform the behaviour (Hsu \& Huang, 2012). Hence the preference to use TPB in studying condom use among the youth in Kibera slum.

This paper focuses on perception of youth towards HIV/AIDS and how this affects condoms use decisions. Based on the literature reviewed, the following hypothesis were formed.

H1: The attitude of Kibera youth towards HIV/AIDS has significant effect on condom use intentions.

$\mathbf{H}_{2}$ : The opinion of parents has significant effect on condom use intentions.

$\mathbf{H}_{3}$ : The opinion of friends has significant effect on condom use intentions

$\mathbf{H}_{4}$ : Youth's risk perception towards HIV/AIDS has a significant effect on their condom use decisions.

\section{Methodology}

\section{Target Population}

Kibera Slum was selected as the area of study because it was the largest slum in Kenya, had high youth population and HIV prevalence had been reported to be high (as highlighted in the background section). Kibera Slum is in Kibra Constituency and considering that the slum covers nearly the whole of the constituency, for the purpose of this study, Kibra Constituency was taken to mean Kibera Slum. The target population of this study was selected from youth aged between 15 and 24 years living in Kibera Slum. These youths share the same residential area, have reasonably similar access to mass media channels and are faced by the same challenges. The total population of Kibra Constituency in 2015 was 201,293 and the youth population was estimated to be over 50,000 (Kenya National Bureau of Statistics (KNBS), 2015). Kibra Constituency has five 
wards. The youth population for the five wards was estimated to be as follows: Laini Saba - 7,000, Lindi - 13,000, Makina- 9,000, Woodley- 8,000 and Sarang'ombe 13,000 (KNBS, 2015).

\section{Sample Size}

The sample size was calculated based on Yamane's formula (Yamane, 1967). This formula was preferred based on Gbegi and Adebisi's (2015) recommendation that it is suitable when dealing with a predetermined population which in this study were youth living in Kibera.

$$
\mathrm{n}=\frac{\mathrm{N}}{1+\mathrm{N}(\mathrm{e})^{2}}
$$

Where,

$\mathrm{n}=$ the sample size

$\mathrm{N}=$ the size of population $(50,000)$

$\mathrm{e}=$ the acceptable margin of error ( 5 percent)

95 percent confidence level and $\mathrm{p}=0.5$ are assumed

Given the target population (N) as 50,000 and assuming an error margin of 5 percent, and a confidence level of 95 percent the resulting sample size (n) is calculated as:

$$
n=\frac{50,000}{1+50,000(0.05)^{2}}=\frac{50,000}{126}=396.825
$$

The researcherss worked with a sample size of 400 respondents. Informed by Ward population as reported by KNBS (2015), the sample consisted of 56 respondents from Laini Saba, 104 from Lindi, 68 from Makina, 64 from Woodley and 108 from Sarang' ombe.

\section{Data collection and hypothesis testing procedure}

Considering the lack of a sampling frame, the researchers sought assistance from local chiefs and Nyumba Kumi (community security groups) leaders on identifying the youth who were staying within their area. Once a potential respondent was identified, after introduction and explanation on need for the study, the respondents were issued with questionnaires to fill as the examiners waited.

Once the required questionnaires were filled, the researchers numbered them and entered the details in SPSS for analysis. The hypothesis stated earlier were then tested using t-test.

\section{Data Analysis}

\section{Response Rate}

The researchers issued 400 copies of the questionnaire to youth living in Kibera Slum, out of which 356 copies were returned duly filled. This represented 89 percent response rate. 


\begin{tabular}{lcc}
\hline Response Rate & Frequency & Percentage \\
\hline Total number invited & 400 & $100 \%$ \\
Total number of responses & 356 & $89 \%$ \\
\hline
\end{tabular}

\section{Demographics}

This first study sought to find age of respondents. The findings show that 61.2 percent of the respondents were aged between 15 and 18 years, 27 percent were aged between 19 and 21 years while 11.8 percent were aged between 22 and 24 years. Thus, findings indicate that the target area had a high concentration of young people. Eighty-eight (88) percent of the respondents were aged between 15 and 21 years. Though the female respondents were slightly more (51.1 percent), the population seemed to be almost balanced in terms of gender, reflecting the Kenyan gender ratio, which is at $50.5 \%$ female and 4.5 male (KNBS, n.d.).

Finding the level of education was important in understanding whether condoms use decisions were influenced by educational level. The results indicated that 40.4 percent of the respondents had attained primary school education, 34 percent had attained secondary school education, 21.3 percent had certificate level education, and 4.3 percent had attained diploma level education while no respondents had a university degree.

The findings indicate that a substantial percentage of the respondents did not have post-secondary education. Seventy-four percent had either primary or secondary level of education compared to 25.6 percent who had either post primary school certificate or diploma level education. While this could be partly attributed to the fact that the target audience was selected from a young generation who could still be in school, there is possibility that it could as well be an indication that slums suffer from poor education levels thus affecting the residents' economic status and ability to make decisions. For instance, Chege and Mwisukha (2013) reported that approximately 60 percent of Kibera youth were had primary school as the highest level of education attained hence could be classified as either illiterate or semi-illiterate. The level of education attained could affect condom use decisions in that increase in education level would probably increase comprehension; hence better judgements of risk behaviours leading to favourable decisions on condoms use.

\section{Hypothesis Testing Results}

H1: The attitude of Kibera youth towards HIV/AIDS has significant effect on condom use intentions.

The test on whether the attitude of Kibera youth towards condoms had a significant effect on condom use intentions had a $p$ value of 0.731 . Hence the equation $t(179)=0.731$ 
, $\mathrm{p}<0.05$, implying that the attitude of Kibera youth had no significant effect on their condom use decisions.

$\mathbf{H}_{2}$ : The opinion of parents has significant effect on condom use intentions.

The t-test on $\mathrm{H}_{2}$ had a $\mathrm{p}$ value of 0.006 . Hence the $\mathrm{t}(179)=0.006, \mathrm{p}<0.05$, implying that the opinion of family members had a significant effect on youth's intention to use condoms.

$\mathbf{H}_{3}$ : The opinion of friends has significant effect on condom use intentions.

$\mathrm{H}_{3}$ had a $\mathrm{p}$ value of 0.203 . Hence the conclusion that the opinion of friends did not have a significant effect on condom use decisions among Kibera youth. $t(179)=0.203, p>0.05$ implying that the opinion friends had no significant effect on youth's intention to use condoms.

$\mathrm{H}_{4}$ : Youth' risk perception towards HIV/AIDS has a significant effect on condom use decisions

$\mathrm{H}_{4}$ had a $\mathrm{p}$ value at 0.452 is greater that alpha value (0.05), hence risk perception has no significant effect on condom use. The mean difference was not significant, t $(179)=0.452$, $p>0.05$. The perceptions of Kibera youth towards HIV/AIDS had no significant effect on their condom use decisions.

\section{Discussion and Conclusion}

Several studies have been done on the sexuality of the youth, with several indicating that the youth are sexually active (e.g. Ndati, 2013; Coma, 2014; NACC, 2015). From the respondents who participated in this study, least half of them (50.4 percent) indicated that they were sexually active. Of the sexually active respondents, 66 percent had their last sex encounter either a week or a month before the date of the study. Only 28.3 percent indicated they were not sexually active.

To understand the kind of sexual relations the respondents had, responds were asked if they were in a relationship. Only 31.7 percent of the respondents indicated that they were in a relationship, suggesting that the majority of the respondents had sex with 'part timers'. Being faithful in a relationship is one of the ways of preventing the spread of HIV/AIDS. Being in a monogamous relationship for people that are not infected reduces chances of infection. The finding that only 30.1 percent of the respondents were in a serious relationship points to the reality that many young people are sexually active but not in committed relationships.

TPB proposes that attitude is a key determinant of behaviour (Ajzen, 1985). However, in this study, the attitude of the youth was found to have no significant effect on their condom use intentions. Whether the attitude of a respondent was favourable or not favourable, there was no effect on their condom use intentions. This was contrary to the assertions of TPB. 
Another assertion of TPB that was tested in this study was the influence of social referents in performing a behaviour. The findings of this study show that parents had significant influence on condom use intentions. This agrees with the assertions of TPB (Ajzen, 1985). The approval of behaviour by relatives contributes greatly to the choices that are made towards performing that behaviour (Hsu \& Huang, 2012).

Peers are assumed to form the reference frame within which youth think and act in addition to being the leading source of emotional support (van de Bongardt et al., 2015). Hence the assumption that friends could have influence on condom use decisions. However, findings of this study show that friends had no significant effect on condom use decisions of the respondents, contrary to what TPB proposes. The difference between the results of this study and TPB assertions, could be in the context of the study. Also, as people grow older, they tend to rely more on their own judgments than the peer influence (van de Bongardt et al., 2015).

Lastly, the study sought to establish how the youth perceived their vulnerability to HIV/AIDS. The respondents were asked to rate their perceived HIV risk as "high", "medium", "low" or "no risk. 31.8 percent perceived their risk as high, 8.5 percent indicated that their risk was medium, 2 percent rated their risk as low while 53.2 percent that they had no risk at all. This means that 55.2 percent of the respondents considered themselves to be at either 'low risk' or at 'no risk' of infection.

More than 50 percent of the youth considered themselves to be invulnerable to HIV/AIDS, yet were sexually active and not using condoms pointed to the possibility that the youth lived a precarious life. This is despite the fact that studies have shown that new infections are high among the youth compared to other groups. As explained by Caldwell and Mathers (2015), the tendency to view risk of infection as low which is common where youth feel they are in committed relationships raises the risk of one getting infected because though they may be sure of their own faithfulness, it is not easy to guarantee that of their partners.

As efforts continue to be made to find a cure for HIV/AIDS, there is need to increase efforts towards reducing the number of new infections especially among the most vulnerable groups. One of those groups is the youth living in slums like Kibera in Kenya. While it is no news that the youth are sexually active, that they are not using condoms and do not view themselves to be at risk of infection should be of concern to communicators. Health communicators should put more focus on making sure that the youth are aware that they are at high risk of HIV/AIDS infection. In addition, factors that lead to youth having a sense of invulnerability towards HIV/AIDS should be addressed.

\section{Suggestions for Further Research}

This study only relied on the youth as the source of data. Consequently, the researchers recommends a study on the attitudes of parents, teachers and religious groups towards condom use by the youth. The researchers further recommends a study on condom use among youth in rural areas. This current study only focused on youth living in urban areas specifically the Kibera Slum. It would be of interest to find out what factors 
influence condom use among the youth in rural areas or other informal settlements in urban areas. Lastly, this study used questionnaires to examine perceptions of youth towards condom use. To give the research further meaning, this study recommends a qualitative in-depth study to understand the sources of myths surrounding invulnerability of youths to HIV infection.

\section{References}

Ajzen, I. (2015). The theory of planned behaviour is alive and well and not ready to retire: A commentary on Sniehotta, Presseau, and Araújo-Soares. Health Psychology Review, 9(2), 131-137. DOI: 10.1080/17437199.2014.883474

Ajzen, I. (1985). From intentions to actions: A theory of planned behavior. In Action control (pp. 11-39). Springer, Berlin, Heidelberg.

Caldwell, K., \& Mathews, A. (2015). The role of relationship type, risk perception, and condom use in middle socioeconomic status black women's HIV-prevention strategies. Journal of black sexuality and relationships, 2(2), 91-120. DOI: 10.1353/bsr.2016.0002

Chege, P., \& Mwisukha, A. (2013). Benefits of slum tourism in Kibera slum in Nairobi, Kenya. International Journal of Arts and Commerce, 2(4), 94-1-2. Retrieved from www.ku.ac.ke

Cohen, S. (2004). Promoting the ' $\mathrm{B}$ ' in ABC: Its value and limitations in fostering reproductive health. The Guttmacher Report on Public Policy, 7(4), 11-13. Retrieved from https://guttmacher.org

Coma, J. C. (2014). HIV prevention and marriage: Peer group effects on condom use acceptability in rural Kenya. Social Science \& Medicine, 116, 169-177. Retrieved from https://doi.org/10.1016/j.socscimed.2014.07.005

Conner, M., \& Armitage, C. J. (1998). Extending the theory of planned behaviour: A review and avenues for further research. Journal of Applied Social Psychology, 28(15), 1429-1464. Retrieved from https://onlinelibrary.wiley.com/doi/abs/10.1111/j.1559-1816.1998.tb01685.x

Edwards, J. K., Bygrave, H., Van den Bergh, R., Kizito, W., Cheti, E., Kosgei, R. J., \& Reid, T. (2015). HIV with non-communicable diseases in primary care in Kibera, Nairobi, Kenya: Characteristics and outcomes 2010-2013. Transactions of The Royal Society of Tropical Medicine and Hygiene, 109(7), 440-446.

Friedland, G. (2016). Marking time in the global HIV/AIDS pandemic. Jama, 316(2), 145146. DOI: $10.1001 /$ jama.2016.9006

Gbegi, D. O., \& Adebisi, J. F. (2015). Analysis of fraud detection and prevention strategies in the Nigerian public sector. Journal of Good Governance and Sustainable Development in Africa, 2(4), 109-128. Retrieved from pdfs.semanticscholar.org

Githugo, W. (2016, April 20). Alarm raised as more youth contract HIV. People Daily, p. 5.

Haley, T., Puskar, K., Terhorst, L., Terry, M. A., \& Charron-Prochownik, D. (2013). Condom use among sexually active rural high school adolescents personal, 
environmental, and behavioural predictors. The Journal of School Nursing, 29(3), 212-224. Retrieved from https://journals.sagepub.com

Hsu, C. H., \& Huang, S. S. (2012). An extension of the theory of planned behaviour model for tourists. Journal of Hospitality $\mathcal{E}$ Tourism Research, 36(3), 390-417. DOI: $\underline{10.1177 / 1096348010390817}$

Kenya National Bureau of Statistics. (2015). Spatial dimensions of well-being in Kenya; where are the poor. Nairobi: Kenya National Bureau of Statistics.

Kenya National Bureau of Statistics,. (n.d.). Home. Retrieved from www.knbs.or.ke

National Aids Control Council. (2015). Kenya's fast-track plan to end HIV and AIDS among adolescents and young people. Nairobi: National Aids Control Council.

National Aids Control Council. (2016). Kenya AIDS Response Progress Report 2016. National Aids Control Council. Nairobi: National Aids Control Council.

Ndati, N. (2013). Social construction of meaning and values regarding HIV and AIDS through interpersonal communication networks: A study of high school students in Nairobi. African Journal of Communication, 1(1), 43-69.

Puffer, E. S., Meade, C. S., Drabkin, A. S., Broverman, S. A., Ogwang-Odhiambo, R. A., \& Sikkema, K. J. (2011). Individual-and family-level psychosocial correlates of HIV risk behaviour among youth in rural Kenya. AIDS and Behaviour, 15(6), 1264-1274. Retrieved from https://link.springer.com/article/10.1007/s10461-0109823-8

Ritchwood, T. D., Ford, H., DeCoster, J., Lochman, J. E., \& Sutton, M. (2015). Risky sexual behaviour and substance use among adolescents: A meta-analysis. Children and Youth Services Review, 52, 74-88. Retrieved from https://www.sciencedirect.com/science/article/pii/S0190740915000882

Santelli, J. S., Speizer, I. S., \& Edelstein, Z. R. (2013). Abstinence promotion under PEPFAR: The shifting focus of HIV prevention for youth. Global Public Health, $8(1), 1-12$. Retrieved from https://www.tandfonline.com/doi/abs/10.1080/17441692.2012.759609

Sivelä, J. (2016). Dangerous AIDS myths or preconceived perceptions? A critical study of the meaning and impact of myths about HIV/AIDS in South Africa. Journal of Southern African Studies, 42(6), 1179-1191. DOI: 10.1080/03057070.2016.1246225

Stutterheim, S. E., Bertens, M. G., Mevissen, F. E., \& Schaalma, H. P. (2013). Factors contributing to inconsistent condom use among heterosexual men in Curacao. Culture, Health $\mathcal{E}$ Sexuality, 15(4), 420-433.

UNAIDS. (2014). The Gap Report. Retrieved from https://www.unaids.org UNAIDS. (2015). AIDS by numbers. Retrieved from https://www.unaids.org Van de Bongardt, D., Reitz, E., Sandfort, T., \& Deković, M. (2015).A meta-analysis of the relations between three types of peer norms and adolescent sexual behavior.Personality and Social Psychology Review, 19(3), 203-234. Retrieved from www.journals.sagepub.com

Wandera, D. A. (2013). The effect of mass media campaigns on sexual behaviour: The case of Mpango Wa Kando Hiv and AIDS campaign in Nairobi West estate, Nairobi County. Nairobi: Daystar University. 
World Health Organization (n.d.). (n.d.). Global All In campaign fights rising HIV infections and deaths among adolescents. Retrieved from http://www.afro.who.int/en/kenya/press-materials/item/7378

Yamane, T. (1967). Statistics: An introductory analysis (2nd ed.). New York: Harper \& Row. 